ECONOMICS

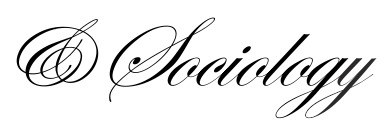

\title{
GENDER AS A FACTOR DETERMINING DECLARATIONS TO COOPERATE AND COOPERATIVE BEHAVIOUR AMONG POLISH STUDENTS
}

\author{
Urszula Markowska- \\ Przybyła, \\ Wrockaw University of Economics, \\ Wrockaw, Poland, \\ E-mail: urszula.markowska- \\ praybyla@ue.wroc.pl

\section{David Mark Ramsey, Wrockaw University of Technology, Wrockaw, Poland, \\ E-mail:david.ramsey@pwr.wroc.pl}

Received: September, 2017

1st Revision: December, 2017

Accepted: January, 2018

DOI: $10.14254 / 2071-$

789X.2018/11-1/14

\begin{abstract}
This article considers the relation between gender and cooperation, measured on the basis of the "Public Goods" game and a questionnaire. Previous studies have not been able to give a clear indication of whether males or females pay more into a common pool, i.e. does one sex show a greater tendency to cooperate? This research presents new results in this field, since it was carried in Poland, where no such large-scale studies have been previously carried out. The study involving 1540 Polish students was carried out in 2014. Three experimental games were used, including the standard one-shot "Public Goods" game.

The results of the study did not find any significant differences in the mean levels of cooperative behaviour based on behaviour in the "Public Goods" game between males and females, although there were some differences between the distributions. There is no clear association between behaviour in this game and home region or the size of a student's home town. On the other hand, there were some clear differences between males' and females' declarations regarding aspects of cooperation. In addition, females demonstrated greater variation in their attitudes according to the region and the size of a home town.
\end{abstract}

Keywords: cooperation; „Public Goods” game; game theory; intention-behaviour gap; Poland

\section{Introduction}

Much research on the differences between sexes has been carried out on the basis of psychology and this has led to increased understanding of differences between the social and economic behaviour of males and females in such areas such as: altruism, aversion to injustice, consumption, investment, attitude to risk, competition and cooperation. However, there is surprisingly little research carried out by psychologists on the last of the mentioned above aspects (Balliet et al., 2011). Women are playing an ever increasing role in social, political and professional life, they are also taking an increasing number of independent decisions. This 
suggests that studies on the differences between the behaviour of males and females would be useful in explaining and understanding various micro- and macroeconomic phenomena.

The goal of this article is to analyse the behaviour of Polish students in the "Public Goods" (PG) game and to test whether the level of cooperation observed depends on the sex of a student. Previous studies have provided ambiguous results regarding this question. Also, this is the first such study to be carried out in one of the countries of Central and Eastern Europe. The declarations of students with regard to their attitudes towards cooperation and actual cooperative behaviour are also analysed. The authors also consider the factors which may influence such behaviour through socialisation or culturalisation: home region, size of a home town (less than 5 ths inhabitants, between 5 and 20 ths, between 20 and 100 ths and above 100 ths) and classification of a home town (rural, urban, metropolitan). Differences according to sex, region and size/category of a home town will be analysed.

This research was carried out on the basis of a study carried out among 1540 Polish students (between 88 and 100 in each of the 16 political regions of Poland) between April and June 2014. The students played three classical experimental games - Trust, Public Goods and Ultimatum, and also completed a questionnaire.

The first section of this paper presents the theoretical background to this research and empirical results from the previous studies in this field. Section 2 describes the experimental procedures. The third section considered the statistical tests used. Section 4 presents the results of the study based on the experimental games and questionnaire. The final section provides a discussion of the results along with the recommendations for future research.

\section{Gender differences regarding cooperation: theory and previous empirical results}

Gender differences, in traits and behaviour, have been the subject of many studies, including experimental studies. They show, among other things, that males are more assertive and have a higher level of self-esteem than females. On the other hand, females exhibit higher levels of extraversion, anxiety and trust, as well as being more emotional (Feingold, 1994). Males show a higher level of independence, self-confidence, assertiveness and competitiveness (agentic attributes), while females exhibit more altruism, empathy and emotional intelligence (communal attributes) (Eagly, 1987). Studies show that females give more support to their friends (Oswald et al., 2004), while males are more ready to help strangers in need (Eagly and Crowley, 1986). Females exhibit a higher level of aversion to risk (Eckel and Grossman, 2008), which may be explained by their emotionality, low levels of self-confidence and treating risk as a threat (whereas males treat it as a challenge) (after: Croson and Gneezy, 2009). There are also differences with regard to social preferences: aversion to inequality (Ockenfels and Bolton, 2000), altruism (Andreoni, 1989), norms of reciprocity (Falk and Fischbacher, 2006) and envy (Mui, 1995). There are also gender differences in the readiness to cooperate, which is the subject of this study.

Experimental results regarding the readiness of males and females to cooperate have been rather ambiguous. Some studies indicate that there are no differences (Andreoni and Petrie, 2008; Cadsby and Maynes, 1998; Sell et al., 1993; Solow and Kirkwood, 2002). Others conclude that females show a greater willingness to cooperate (Eckel and Grossman, 2008; Nowell and Tinkler, 1994; Seguino et al., 1996), while some show that males are more cooperative (Brown-Kruse and Hummels, 1993; Sell and Wilson, 1991; Solow and Kirkwood, 2002). The results of a recent meta-analysis (Balliet et al., 2011), which took into account 272 studies based on experimental economics, indicated that there are no significant gender differences. However, these results are very sensitive to the particulars of a study and its context. It has been found that the passing of time has influenced results, due to changes in 
socio-economic conditions over the past 50 years. Studies have shown that the conclusions depend on the social environment and whether a society is matriarchal or patriarchal (Andersen et al., 2008).

Psychologists indicate that social cues (norms) have a greater impact on the behaviour of females than on the behaviour of males (Gillian, 1982). Hence, even subtle changes in the form of an experimental game can have a significant effect on results, as shown by the study of e.g. Chermak and Krause (2002). Studies have shown that when individuals know their roles in the PG game, then gender differences become significant - in this case females pay more on average into the pool than males. When players are not given specific roles, then gender differences become insignificant. (Croson and Gneezy, 2009) came to a similar conclusion in their meta-analysis when they noticed that there was a greater variation in the behaviour of females, both within and between studies.

Social psychology presents various theories to explain gender differences in behaviour. Socio-cultural and evolutionary explanations are of particular importance. However, there have been relatively few studies regarding differences in attitudes towards cooperation according to sex (Balliet et al., 2011). According to socio-cultural theory, the source of the differences in social behaviour according to sex lies in the differing ways in which males and females are socialised and experience social life. Based on this perspective, the main factor differentiating the behaviour of males and females is the different proportion of males and females in given social roles and positions in the hierarchy (Eagly and Wood, 1999). This is used to explain the difference between males and females when faced with social dilemmas involving cooperation, including caring about the well-being of others (communal orientation). Based on this, it is argued that females are more cooperative, which is in accordance with sexual stereotypes (Deaux and Lewis, 1984). It has been noted that women are aware of such expectations in the face of social dilemmas (Greig and Bohnet, 2009), which creates a form of feedback loop.

The theory of evolution states that the differing selection pressures on the psyche of males and females, due to the different problems they have faced, resulted in behaviour differing according to sex. The decision rules applied by members of the two sexes have evolved to make use of interactions with others in different environments These gender differences have been formed by a long process of natural and sexual selection and the differences between today's males and females are responses to these different environmental constraints (Balliet et al., 2011). Lotito, Migheli and Ortona (2013) conducted a study on cooperation in the light of this theory with the aim of discovering whether cooperation is instinctive or rational. The results seem to indicate that cooperation is instinctive and that ,avoiding cooperation" (defection) is the result of a rational decision and the behaviour of females is less instinctive than that of males.

\section{The study procedure}

The study was based on three experimental games and a questionnaire. The basis for this study on cooperation was the Public Goods game, which places the participants in the role of making a decision on a scale between completely egoistic behaviour and completely cooperative behaviour, where cooperation has benefits for the group as a whole. A four-player, one-play version of the game was used in our study, where participants were chosen at random from those in the current session and players did not know who they were playing with or what sex they were.

The experiments were carried out at the state university in each of the 16 cities listed between 16.04.2014 and 12.06.2014. At each site, there were between 88 and 100 students (see Table 1). All the studies were carried out at universities, which give courses in a wide range of 
subjects, rather than more specialist institutions, in order to obtain a wide profile of students in each city ${ }^{1}$.

The experiments were conducted by "EU-CONSULT" Ltd. under the supervision of Dr. Urszula Markowska-Przybyła and Ewa Starczewska, both from the Faculty of Economics, Management and Tourism of Wrocław University of Economics, based in Jelenia Góra, where a pilot study was observed by both authors on 11.03.2014. At each site, the students were split into three or four sessions (on average there were around 30 participants in a session), run in immediate succession. Statistical analysis indicated that the decisions made in the games did not depend on the session number, nor the number of participants in a session. Each session lasted about an hour. On average, students obtained a payoff of around 45PLN (approx. $€ 11$ ). All decisions and questionnaires were written on forms which were coded to identify the player and their "opponents" in the relevant games. In each session, students were split randomly into two groups (without knowing which group any of the other players were in). They first made their decision in the Public Goods Game and the decision of Player 1 in the game appropriate to their group (the Trust Game or the Ultimatum Game). The players then obtained the appropriate instructions for Player 2 in the game they had not played yet, together with the decision of the student randomly assigned to them (who played the role of Player 1). These decisions were collected and the payoffs calculated, while the students filled in the questionnaire. Filling in the questionnaire took 20 to 30 minutes and was required for the students to obtain their payoff. These decisions were then collected, the individual payoffs calculated and the students paid.

Table 1. Structure of the study group according to sex and region

\begin{tabular}{lcccc}
\hline \multirow{2}{*}{ Region } & \multicolumn{2}{c}{ Females } & \multicolumn{2}{c}{ Males } \\
\cline { 2 - 5 } & Number & $\%$ in region & Number & $\%$ in region \\
\hline Dolnośląskie & 73 & $76.00 \%$ & 23 & $24.00 \%$ \\
\hline Kujawsko-Pomorskie & 80 & $80.00 \%$ & 20 & $20.00 \%$ \\
\hline Lubelskie & 68 & $77.30 \%$ & 20 & $22.70 \%$ \\
\hline Lubuskie & 51 & $51.00 \%$ & 49 & $49.00 \%$ \\
\hline Łódzkie & 75 & $75.00 \%$ & 25 & $25.00 \%$ \\
\hline Małopolskie & 67 & $69.80 \%$ & 29 & $30.20 \%$ \\
\hline Mazowieckie & 70 & $79.50 \%$ & 18 & $20.50 \%$ \\
\hline Opolskie & 74 & $77.10 \%$ & 22 & $22.90 \%$ \\
\hline Podkarpackie & 79 & $79.00 \%$ & 21 & $21.00 \%$ \\
\hline Podlaskie & 72 & $75.00 \%$ & 24 & $25.00 \%$ \\
\hline Pomorskie & 77 & $77.00 \%$ & 23 & $23.00 \%$ \\
\hline Śląskie & 72 & $75.00 \%$ & 24 & $25.00 \%$ \\
\hline Świętokrzyskie & 68 & $68.00 \%$ & 32 & $32.00 \%$ \\
\hline Warmińsko-Mazurskie & 56 & $58.30 \%$ & 40 & $41.70 \%$ \\
\hline Wielkopolskie & 77 & $77.00 \%$ & 23 & $23.00 \%$ \\
\hline Zachodniopomorskie & 60 & $68.20 \%$ & 28 & $31.80 \%$ \\
\hline Total & 1119 & $72.66 \%$ & 421 & $27.34 \%$ \\
\hline
\end{tabular}

Source: own research.

\footnotetext{
${ }^{1}$ A more detailed description of the study procedure and group is contained in the following papers: (MarkowskaPrzybyla and Ramsey, 2014, 2015).
} 
In the Public Goods (PG) game (Isaac and Walker, 1988), the participants decide how much money from a given amount at their disposal should be paid into a common pool. This decision is made without knowing the decisions of any of the other players. The funds in the common pool are then multiplied by a factor greater than 1, but smaller than the number of players. This pool is then split equally between all the players, independently of how much each initially paid into the pool. A Nash equilibrium satisfies the constraint that each player maximizes his/her own payoff given the decisions of the other players. In the PG game, no matter what the decisions of the other players are, an individual maximises his/her payoff by not paying anything into the pool (i.e. this decision ,,dominates” any other decision a player can make). It follows that at the unique Nash equilibrium of this game, none of the players pay anything into the pool (Rosenthal, 1973). Behaviour corresponding to the Nash equilibrium is observed relatively rarely in experiments (Gunnthorsdottir et al., 2007), although the players have no personal incentive to pay anything into the pool (i.e. most participants behave differently to homo oeconomicus). The total sum of the payoffs reflects the level of cooperation in the group as a whole, while individuals playing the role of a "free rider" obtain a greater payoff than those paying money into the pool. Hence, each player is faced by choosing between gains for the group as a whole and individual gains. Cooperation can bring personal gains, but there exists a risk that the cost of such cooperation is greater than results from the level of cooperation in the group as a whole. On the other hand, free riders gain from any cooperation from the other players. Hence, behaviour in this game illustrates individuals' level of trust that other players will show cooperative behaviour. In the study, each player had 20 PLN at his/her disposal, the amount paid into the pool was multiplied by a factor of 1.6, and each group contained 4 players.

The study also used a questionnaire, which included the following questions regarding issues directly or indirectly related to cooperation:

- In the course of the last year, have you acted as a volunteer in any undertaking on behalf of local society? (variable „volunteer”), possible answers: yes, no.

- How much does it concern you that other people pay less tax than they should do? (variable „taxes”), possible answers: not at all, not much, difficult to say, somewhat, a lot.

- Do you react when somebody is damaging public property, e.g. you intervene or call the appropriate authorities? (variable ,public property”), possible answers: never, very rarely, sometimes, generally.

- Which of the following strategies is most likely to bring success: above all individual effort with a minimum of cooperation, or cooperation? (variable „strategy 1”).

Other questions included:

- The trust question (Do you think that the majority of people can be trusted?). Trust is a major factor in determining one's willingness to cooperate.

- Do you prefer inhabitants of your own region to inhabitants of other regions when making economic decisions, if other factors are unimportant? Possible answers: yes, no. One's level of association with such a group might be a factor determining the willingness to cooperate.

- Are you an active participant in an organisation? Possible answers: yes, no. This might be an indicator of willingness to cooperate.

- How interested are you in local matters? - Measured on a five-point scale.

The following questions might give light to the type of cooperation that is preferred:

- Which of the following strategies is most likely to bring success: acting in line with the law, acting on or beyond the boundaries of the law? 
- What principles are more important to you in situations of conflict: legal norms or ethical norms? Possible answers: legal norms (even when they conflict with ethical norms), ethical norms (as long as the penalty for breaking legal norms is not great), ethical norms are the most important.

\section{Statistical Analysis}

In order to analyse whether the mean amounts paid into the pool by two groups differ, the t-test for two samples was used without assuming that the variances were equal, unless the sample sizes involved were not large $(<30$, this was generally the case when looking for a difference between the sexes at the level of a region). In this case, the non-parametric MannWhitney (M-W) test was used, since the data did not follow a normal distribution. For this reason when analysing the difference between the mean amounts paid into the pool for a larger number of groups, the non-parametric Kruskal-Wallis test was used.

In order to analyse whether there was an association between two nominal variables (categorical variables without a natural ordering), Fisher's exact test for independence was used, unless the number of categories was too large for numerical calculations (e.g. when region was one of the variables). In this case, the chi-square test for independence was applied.

To analyse systematic differences between the distributions of ordinal variables (categorical variables with a natural ordering) according to group, the Mann-Whitney test was used (for two groups) or the Kruskal-Wallis test (for three groups or more). To detect general differences between the distributions of such variables, the appropriate test of independence was used (according to the number of categories).

A non-parametric test of correlation (Spearman's) was used to analyse the association between pairs of ordinal variables and between an ordinal variable and the amount paid into the pool in the PG game.

In all cases, we applied a 5\% significance level and report the corresponding p-value to give information about the strength of evidence for an association (the smaller the $\mathrm{p}$-value, the greater the evidence for an association).

\section{The relationship between gender and cooperation amongst Polish students}

An earlier article of the authors (Markowska-Przybyla and Ramsey, 2015) showed that gender was an important factor affecting many of the declarations of the students in the questionnaire. This would suggest that gender plays an important role in modulating the observed behaviour of individuals. It should be noted that the study does not cover the entire scope of cooperative behaviour, but just a few chosen aspects.

Females transferred a slightly higher proportion of their funds than males on average $(60.47 \%$ vs. $58 \%)$. However, these differences were not statistically significant ( $\mathrm{p}=0.1193$, ttest). Figure 1 presents the empirical distribution of the amount paid into the pool according to sex.

It should be noted that the students did not know who they were playing with, but they could see the other participants in the session. It is thus possible that the behaviour observed could be associated with the sex ratio in a session. Analysis of the correlation between the proportion of participants being female in a session and the payments made into the pool did not indicate that such an association existed.

Although there is no significant difference between the mean amounts given, there are significant differences between the distributions of the amount paid into the pool according to 
sex. Both of these distributions have local maxima when the amount paid into the pool is a multiple of five, i.e. at $0,5,10,15$ and 20 . Males are more than twice as likely to play the role of a free-rider $(6.4 \%$ vs $2.8 \%, p=0.0014$, Fisher's exact test), while females are significantly more likely to pay half of their funds into the pool ( $36.4 \%$ vs $27.6 \%, p=0.0011$, Fisher's exact test). These results generally agree with the observations that males have a greater tendency to behave individualistically, while females tend to be risk averse (Borghans et al., 2009).

In terms of the declarations made in the questionnaire, there are a number of significant differences according to sex: males declare a higher readiness to react when public property is being damaged (M-W test, $\mathrm{p}=0.0040)$ and are more likely to be active in an organisation (Fisher's test, $\mathrm{p}=0.0057$ ) $-41.3 \%$ of males declared that they were involved in an organisation and $34.1 \%$ of females. Females declared a higher level of trust (M-W test, $\mathrm{p}=0.0003)$, although males transferred more money on average in the trust game ( $\mathrm{t}$-test, $\mathrm{p}=0.0206)$. Females are more interested than males in local matters (M-W test, $\mathrm{p}=0.0390)$ and are more likely to have a preference for inhabitants from their own region than males do (Fisher's exact test, $\mathrm{p}=0.0187$ ). Moreover, females are more likely to state that the type of strategy most likely to bring success involves acting in line with the law (77.0\% of females, compared to $55.8 \%$ of males, Fisher's exact test, $\mathrm{p}=0.0000$ ). On the other hand, males are more likely to choose one of the extreme options when stating the importance of legal and ethical norms, while females are more likely to choose the central option (ethical norms are more important, as long as the penalty is not too high, Fisher's exact test, $\mathrm{p}=0.0382$ ) Such declarations are in line with the sex stereotypes outlined in the theoretical section, but are less visible in the behaviour observed in the "Public Goods" game.

It should be noted that there is a positive correlation between the amount an individual paid into the pool in the PG game and the amount he/she offers in the Ultimatum game, regardless of sex (Spearman's test of correlation, for females $r=0.1379, p=0.0015$; for males $\mathrm{r}=0.1808, \mathrm{p}=0.0049$ ). Females who state that the strategy most likely to bring success involves cooperation pay more on average into the pool than those who state that such a strategy involves relying on one's own effort ( 12.60 vs 10.80 , two sample t-test $\mathrm{p}=0.0000)$. On the other hand, the amount paid into the pool by males is positively associated with acting as a volunteer ( $\mathrm{t}-$ test, $\mathrm{p}=0.0477$, male volunteers pay 12.21 into the pool on average and non-volunteers 11.11) and active participation in a formal organisation (members give 12.36 on average, nonmembers give 11.03 , two sample t-test, $\mathrm{p}=0.0170$ ). These results suggest that the behaviour of females is associated with their declared attitudes and opinions towards trust and cooperation, while males' behaviour is associated with their engagement in social life (membership in organisations and engagement in the local community). 


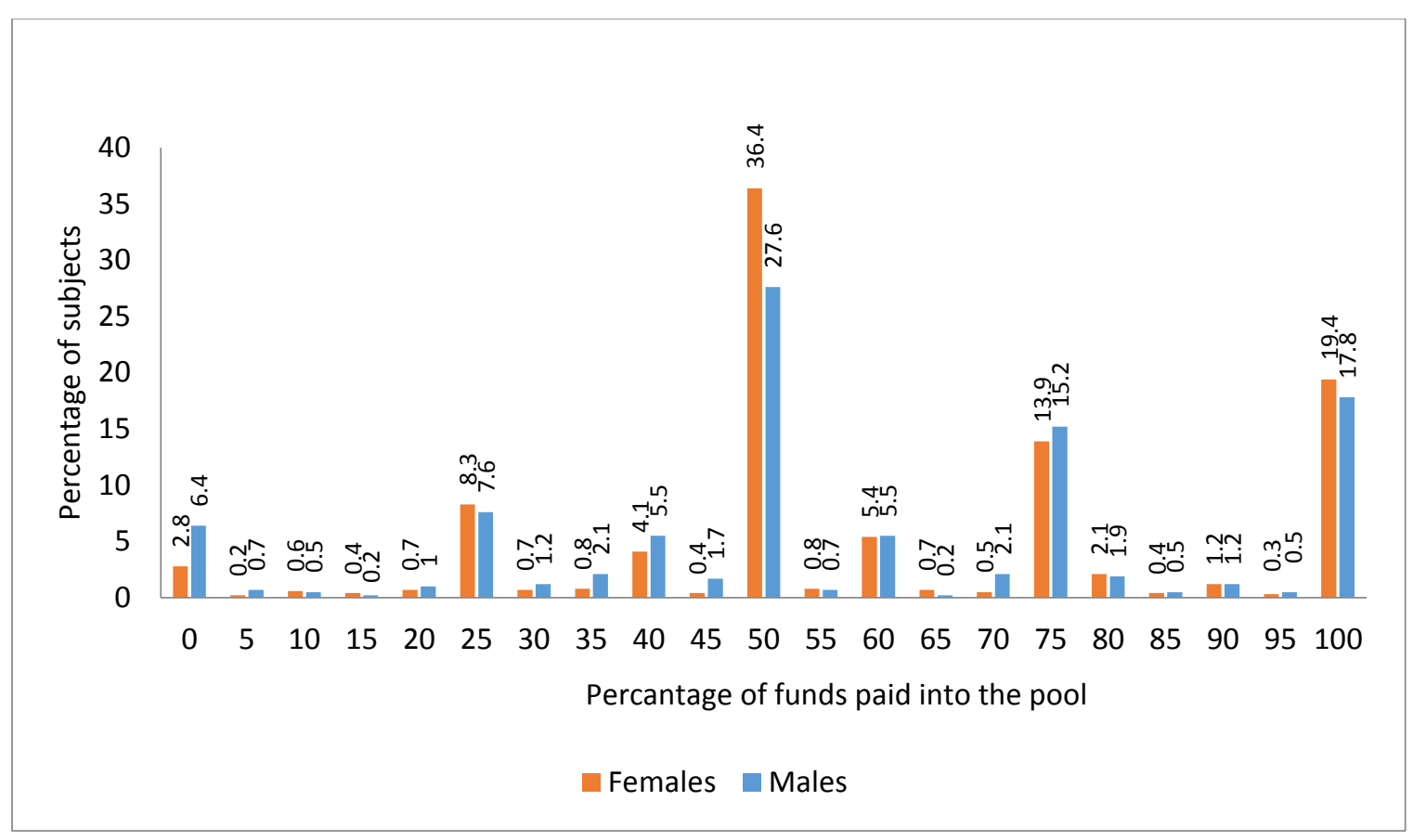

Figure 1. The empirical distribution of the amount paid into the pool according to sex Source: authors' own data.

Based on sociocultural theory, the differences between males and females may be an effect of various forms of socialisation, role models and differing modes of participation by males and females at various steps in the social hierarchy, as well as cultural differences (Kashima et al., 1995). Hence, we now analyse the variables which may be associated with such sociocultural factors. The region from which a student comes and the classification and size of their home town are such variables. Thus the authors test whether these variables were associated with a difference between the level of cooperation declared or displayed by males and females or any other factor associated with the level of cooperation. It should be noted that the variable "classification of home town" is very strongly associated with a town's size. The category "metropolis" covers the largest cities and the urban conurbations around Gdańsk and Katowice, while smaller cities are included in the "town" category.

Firstly, we analysed the relation between the amount of money paid into the pool and the geographical location of a student's home region. This may indicate that different regions or environments exhibit different behavioural, cultural or social norms, which might affect males and females in different ways. There is a weak, but significant positive correlation between how far north a student comes from (based on the latitude of the capital city) and the amount of money paid into the pool (Spearman's test of correlation, $r=0.0670, p=0.0249$ ). The relation between the difference between the amount paid into the pool according to sex and geographical location was analysed in a similar way on the basis of the standardised differences between the mean amount paid into the pool by males and females according to their home region. No significant correlation was found. The only significant difference between the mean amounts paid into the pool by males and females within a home region was in the Lubuskie region ( $\mathrm{M}-\mathrm{W}$ test, $\mathrm{p}=0.0390$ ). However, the numbers of males and females from this region in the study group were both relatively large and this difference was not significant according to the t-test $(\mathrm{p}=0.0675)$. 
We then analysed whether the size of a student's home town modulated the relation between behaviour and gender. No difference was observed between the mean amount given by males or females in any of the three categories of home district (rural, town, metropolis) or according to the size of the student's home town (split into four categories, village - less than 5 thousand, small town - between 5 and 20 thousand, large town - between 20 thousand and 100 thousand, city - more than 100 thousand). On the other hand, the size of a student's home town modulated the relation between gender and the five following variables: membership in organisations, declared level of trust, the amount transferred in the Trust game, declared intention to react when public property is being damaged and level of interest in local matters.

The proportion of males involved in organisations increases with the size of their home town, while the likelihood of a female being a member of an organisation does not depend on the size of her home town. As a result, males from cities are more likely to be members of organisations than females from cities (Fisher's exact test, $p=0.0088$ ). No significant association between gender and organisational membership exists for students from villages or towns. Similarly, the difference between the expressed levels of trust according to gender are most visible in cities. Males' declared level of trust tends to decrease as the size of their home town increases. Females in cities declare a higher level of trust than males from cities (M-W test, $\mathrm{p}=0.0001$ ), whereas there is no significant association between the declared level of trust and gender among students from towns and rural areas.

On the other hand, the largest difference between males and females with respect to declared intention to react when public property is damaged is most visible in rural areas. Males from rural areas declare a stronger intention to react when public property is being damaged than females from rural areas $(\mathrm{M}-\mathrm{W}$ test, $\mathrm{p}=0.0130)$. As the size of a student's home town increases, males' declared intention to react when public property is being damaged becomes weaker. Males from rural areas transfer more on average than females from rural areas (5.50 vs 4.39, t-test, $\mathrm{p}=0.0415$ ).

The level of interest in local matters according to sex also differs only in rural areas. Females from rural areas show a greater interest in local matters ( $t$-test, $p=0.0371)$. As the size of a student's home town increases, females' interest in local matters tends to decrease (Spearman test for correlation, $r=--0.0973, p=0.0012$ ), while males' interest in local matters does not change overall.

Next, we analysed how the behaviour of males and females, as separate groups, is associated with region and the size of the home town (see Table 2). It should be noted that region is a nominal variable, while the nature and size of the home town are ordinal variables.

Neither home region, nor the size of a student's home town, are significantly associated with the amount paid into the pool in the PG game (the variation in payments by females according to region is only significant at the $10 \%$ level).

Females showed more variation in their declarations according to region and the size and classification of their home town.

Amongst females, the frequency of the following indicators of cooperation are modulated by region: preference for those from the same region (Chi-square test of independence, $p=0.001)$, interest in local matters $(p=0.009$, Kruskal-Wallis test $)$, and attention to tax evasion ( $\mathrm{p}=0.028$, Kruskal-Wallis test) (see Fig. 2). Preference for those from the same region is highest in Podlaskie, Podkarpackie and Świętokrzyskie. These are all rural regions located in the east of Poland. The lowest levels of such a preference are in Małopolskie, Zachodniopomorskie and Mazowieckie. The second of these regions is in the north-west corner of Poland and was one of the regions which joined Poland after World War II. The capitals of the other two regions are the largest cities in Poland, which attract immigrants from other regions. The highest level of interest in local matters is exhibited in southern regions (Lubuskie, 
Małopolskie, Podkarpackie). Most interest in the phenomenon of tax avoidance was noted in the south-west (Lubuskie, Dolnośląskie) and Kujawsko-Pomorskie.

Table 2. Results of tests of association between sociocultural factors and indicators of cooperative behaviour (given by p-values) according to sex

\begin{tabular}{|c|c|c|c|c|c|c|}
\hline \multirow{3}{*}{ Indicator of cooperative behaviour } & \multicolumn{6}{|c|}{ Grouping (sociocultural) variable } \\
\hline & \multicolumn{2}{|c|}{ Home Region } & \multicolumn{2}{|c|}{$\begin{array}{l}\text { Nature of home } \\
\text { town }\end{array}$} & \multicolumn{2}{|c|}{ Size of home town } \\
\hline & $\mathrm{F}$ & $\mathrm{M}$ & $\mathrm{F}$ & $\mathrm{M}$ & $\mathrm{F}$ & $\mathrm{M}$ \\
\hline \multirow{2}{*}{ Amount paid into the pool } & \multirow{2}{*}{$0.073(\mathrm{~K})$} & \multirow{2}{*}{$0.183(\mathrm{~K})$} & $0.587(\mathrm{~K})$ & $0.502(\mathrm{~K})$ & $0.620(\mathrm{~K})$ & $0.418(\mathrm{~K})$ \\
\hline & & & $0.310(\mathrm{~S})$ & $0.264(\mathrm{~S})$ & $0.406(\mathrm{~S})$ & $0.191(\mathrm{~S})$ \\
\hline \multirow{2}{*}{ Acted as a volunteer } & \multirow{2}{*}{$0.894(\mathrm{C})$} & \multirow{2}{*}{$0.189(\mathrm{C})$} & $0.049(F)$ & $0.637(\mathrm{~F})$ & $0.002(\mathbf{F})$ & $0.376(\mathrm{~F})$ \\
\hline & & & $0.024(\mathrm{~A})$ & $0.918(\mathrm{~A})$ & $0.000(A)$ & $0.909(\mathrm{~A})$ \\
\hline \multirow{2}{*}{ Reaction to public goods being damaged } & \multirow{2}{*}{$0.352(\mathrm{~K})$} & \multirow{2}{*}{$0.070(\mathrm{~K})$} & $0.780(\mathrm{~K})$ & $0.480(\mathrm{~K})$ & $\mathbf{0 . 0 3 3}(\mathrm{K})$ & $0.805(\mathrm{~K})$ \\
\hline & & & $0.529(\mathrm{~S})$ & $0.478(\mathrm{~S})$ & $0.897(\mathrm{~S})$ & $0.330(\mathrm{~S})$ \\
\hline \multirow{2}{*}{$\begin{array}{l}\text { Does it bother you that others pay lower } \\
\text { taxes than they should? }\end{array}$} & \multirow{2}{*}{$\mathbf{0 . 0 2 8}(\mathbf{K})$} & \multirow{2}{*}{$0.124(\mathrm{~K})$} & $0.296(\mathrm{~K})$ & $0.643(\mathrm{~K})$ & $0.111(\mathrm{~K})$ & $0.771(\mathrm{~K})$ \\
\hline & & & $0.126(\mathrm{~S})$ & $0.353(\mathrm{~S})$ & $0.068(\mathrm{~S})$ & $0.790(\mathrm{~S})$ \\
\hline \multirow{2}{*}{$\begin{array}{l}\text { Strategy most likely to bring success } \\
\text { [individual effort /cooperation] }\end{array}$} & \multirow{2}{*}{$0.737(\mathrm{C})$} & \multirow{2}{*}{$0.215(\mathrm{C})$} & $0.387(\mathrm{~F})$ & $0.451(\mathrm{~F})$ & $0.122(\mathrm{~F})$ & $0.540(\mathrm{~F})$ \\
\hline & & & $0.298(\mathrm{~A})$ & $0.206(\mathrm{~A})$ & $0.037(\mathrm{~A})$ & $0.217(\mathrm{~A})$ \\
\hline \multirow{2}{*}{$\begin{array}{l}\text { Amount transferred by the player in the } \\
\text { Trust game (Kruskal-Wallis test) }\end{array}$} & \multirow{2}{*}{$0.573(\mathrm{~K})$} & \multirow{2}{*}{$0.470(\mathrm{~K})$} & $0.432(\mathrm{~K})$ & $0.755(\mathrm{~K})$ & $0.281(\mathrm{~K})$ & $0.071(\mathrm{~K})$ \\
\hline & & & $0.205(\mathrm{~S})$ & $0.765(\mathrm{~S})$ & $0.081(\mathrm{~S})$ & $0.900(\mathrm{~S})$ \\
\hline \multirow{2}{*}{ Declared level of trust } & \multirow{2}{*}{$0.466(\mathrm{~K})$} & \multirow{2}{*}{$0.201(\mathrm{~K})$} & $0.283(\mathrm{~K})$ & $0.528(\mathrm{~K})$ & $0.023(K)$ & $0.311(\mathrm{~K})$ \\
\hline & & & $0.113(\mathrm{~S})$ & $0.714(\mathrm{~S})$ & $0.120(\mathrm{~S})$ & $0.071(\mathrm{~S})$ \\
\hline \multirow{2}{*}{ Interest in local matters } & \multirow{2}{*}{$0.009(K)$} & \multirow{2}{*}{$0.369(\mathrm{~K})$} & $0.041(K)$ & $0.456(\mathrm{~K})$ & $0.007(K)$ & $0.912(\mathrm{~K})$ \\
\hline & & & $0.014(\mathrm{~S})$ & $0.442(\mathrm{~S})$ & $0.001(S)$ & $0.645(\mathrm{~S})$ \\
\hline \multirow{2}{*}{$\begin{array}{l}\text { Preference for individuals from the same } \\
\text { region }\end{array}$} & \multirow{2}{*}{$0.001(C)$} & \multirow{2}{*}{$0.399(\mathrm{C})$} & $0.571(\mathrm{~F})$ & $0.143(\mathrm{~F})$ & $0.839(\mathrm{~F})$ & $0.680(\mathrm{~F})$ \\
\hline & & & $0.762(\mathrm{~A})$ & $0.176(\mathrm{~A})$ & $0.446(\mathrm{~A})$ & $0.387(\mathrm{~A})$ \\
\hline Active particination in an organisation & $0.312(\mathrm{C})$ & $0054(C)$ & $0.506(\mathrm{~F})$ & $0.203(\mathrm{~F})$ & $0.689(\mathrm{~F})$ & $0.143(\mathrm{~F})$ \\
\hline Active participation in an organisation & $0.312(\mathrm{C})$ & $0.054(\mathrm{C})$ & $0.743(\mathrm{~A})$ & $0.076(\mathrm{~A})$ & $0.779(\mathrm{~A})$ & $0.176(\mathrm{~A})$ \\
\hline Relative importance of legal and ethical & $0.888(\mathrm{~K})$ & $0.512(\mathrm{~K})$ & $0.763(\mathrm{~K})$ & $0.004(K)$ & $0.918(\mathrm{~K})$ & $0.042(K)$ \\
\hline norms & $0.888(\mathrm{~K})$ & $0.512(\mathrm{~K})$ & $0.724(\mathrm{~S})$ & $0.001(S)$ & $0.659(\mathrm{~S})$ & $0.007(\mathrm{~S})$ \\
\hline Strategy most likely to bring success & & & $0.653(\mathrm{~F})$ & $0.201(\mathrm{~F})$ & $0.346(\mathrm{~F})$ & $0.036(F)$ \\
\hline $\begin{array}{l}\text { [following the law/acting on the borderline } \\
\text { of the law] }\end{array}$ & $0.337(\mathrm{C})$ & $0.782(\mathrm{C})$ & $0.388(\mathrm{~A})$ & $0.674(\mathrm{~A})$ & $0.069(\mathrm{~A})$ & $0.027(\mathrm{~A})$ \\
\hline
\end{tabular}

Note: K- Kruskal-Wallis test, F-Fisher's exact test, C-Chi-square test of independence, S-Spearman's correlation coefficient, A- Mann-Whitney test. Significant results in bold.

Source: authors' own analysis.

Again among females, the frequency of the following indicators of cooperation are modulated by the size and/or classification of their home town: being a volunteer (size and classification, Mann-Whitney test, $\mathrm{p}=0.000$ and $\mathrm{p}=0.024$, respectively), interest in local matters (size and classification, Spearman's test of correlation, $p=0.001$ and $p=0.014$, respectively), declared level of trust (size, Kruskal-Wallis test, $\mathrm{p}=0.023$ ), reaction to public property being damaged (size, Kruskal-Wallis test, $\mathrm{p}=0.033$ ), stating that the strategy most likely to bring success involves individual effort (size - Mann-Whitney test, $\mathrm{p}=0.037$ ). Females are more likely to be volunteers, but become less interested in local matters, as the size of their home town grows. Females from small towns declare a higher readiness to react when public property is being damaged and the highest level of trust. The larger the size of a female's home town, the more likely she is to state that the strategy most likely to bring success involves individual effort.

Among males, the frequency of the following indicators of cooperation are modulated by size and/or classification of their home town: the relative importance of ethical norms 
compared to legal norms (size and classification, $\mathrm{p}=0.007$ and $\mathrm{p}=0.001$, respectively, Spearman's test of correlation), stating that the strategy most likely to bring success involves acting on the edge of the law (size, Spearman's test of correlation, $\mathrm{p}=0.027$ ). The larger the size of their home town, the more likely males are to place ethical norms above legal norms and state that the strategy most likely to bring success involves acting on the edge of the law.

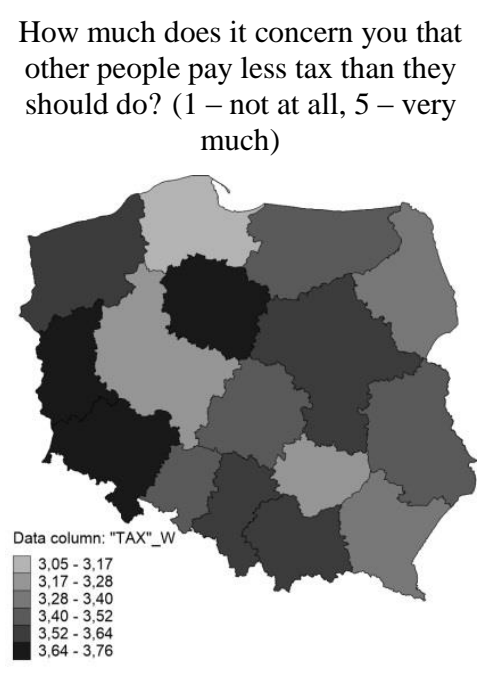

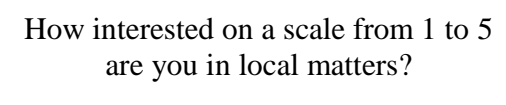

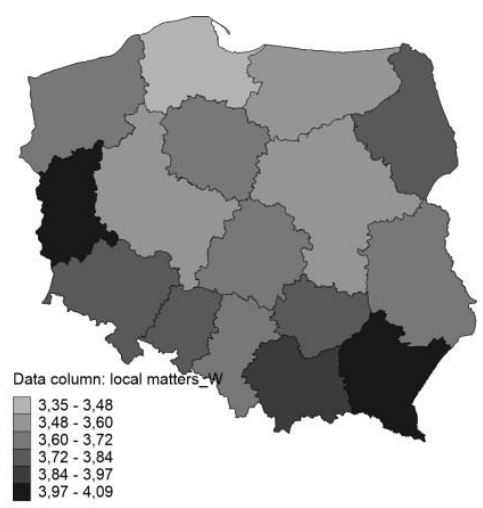

Do you have a preference for inhabitants of your own region in economics matters when other factors are unimportant? (percentage of positive answers)

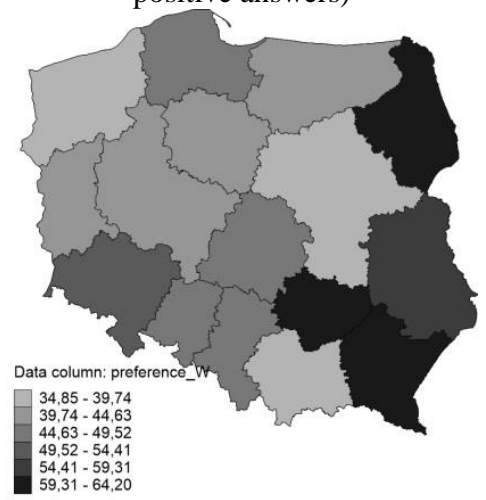

Figure 2. Regional differences in various declarations by females Source: based on authors' own data.

\section{Summary}

Previous studies have not given a clear answer as to whether gender is a significant factor in determining the amount paid into the pool in the Public Goods game. In our study, females did pay a higher proportion into the pool than males $(60.47 \%$ vs. $58 \%)$, but this difference is not statistically significant. However, there are a couple of significant, but subtle, differences between the distributions of these payments, which correspond to previously observed gender differences. In particular, males are significantly more likely not to pay anything into the pool and females are more likely to pay precisely $50 \%$ of the funds available to them into the pool. Additionally, no significant differences between males and females is observed at the regional level or according to the size of a student's home town.

Analysis of the amounts paid into the pool does not indicate that home region or size of home town, factors associated with the socialisation of individuals, has any effect on the behaviour of students, male or female, in the PG game. Also, the mean level of cooperation of males and females was comparable, regardless of region or size of home town.

However, there are gender differences regarding the declarations of students about attitudes related to cooperation and engagement. Females show a higher level of regional variation in their declarations, which agrees with previous results described in the introduction, according to which females are more sensitive to their surrounding environment. For example, (Lewicka, 2013) notes that gender is associated with an individual's identity and how they relate to their home region.

There are significant gender differences in several dimensions. Males declare a higher readiness to intervene when they see that public property is being damaged and are more likely to be active in a formal organisation. They also transfer on average a higher sum in the Trust game. On the other hand, females declare a higher level of trust, are more interested in local 
matters and are more likely to prefer inhabitants of their home region in economic relations than males are. Females are more likely to declare that the strategy most likely to bring success involves acting in line with the law, rather than on the boundary of the law. However, males are more likely to state that legal principles take precedence over ethical principles. Although females declare a higher willingness to cooperate (e.g. a higher level of trust), males are more likely to exhibit cooperation in experimental games or declare active participation in cooperative activities. This apparent intention-behaviour gap may result from females' higher level of aversion to risk. Females identify more strongly with their local society (local matters and inhabitants) and observing the law, while more frequently balancing the priority of legal and ethical principles, i.e. stating that ethical norms take precedence only when legal punishments are minimal.

The results from the questionnaire indicate that several gender differences are modulated by the local environment (home region, size of home town). In small towns, males declare a higher willingness to intervene when public property is being damaged. Females from cities declare a higher level of trust than males from cities, while in rural areas there is no such difference. Females are more likely to express an economic preference for inhabitants of their home region, especially in the rural eastern regions. Males from cities are more likely to be active in organisations than females from cities, although among those from rural areas, there is no such difference.

„Region” is a factor determining aspects of cooperative behaviour among females: concern about individuals paying less tax than they should, interest in local matters and preference for local inhabitants. The highest level of concern about taxes was expressed in the south-west and Kujawsko-Pomorskie. The highest levels of interest in local matters and preference for local inhabitants was expressed in the south and east, respectively.

The interest declared by females in local matters declines as the size of their home town increases. However, females from large towns and cities are more likely to be volunteers than females from more rural areas. The highest level of willingness to intervene when public property is being damaged is declared by females from small towns (5-20 thou. inhabitants).

On the other hand, the size of a student's home town modulates the behaviour of males in a different dimension, namely their attitude towards legal norms. Males from cities are more likely to state both that ethical principles take precedence over legal principles and that the strategy most likely to bring success involves acting on the boundary of the law than males from rural areas or small towns. One should take into account that since the number of males in the sample was clearly lower than the number of females, the power to find significant associations between a student's home environment and declarations/behaviour of males is lower than for females. However, the significance of some of the results regarding females and the nature of the differences described above are clear evidence that, statistically speaking, males and females react to their home environment in different ways. The local environment affects a female's level of engagement in matters of the local community (interest in local matters and engagement in them, preference for local inhabitants), while affecting a male's attitude to the relation between legal and ethical norms.

Analysis of the results also indicates that there exists an intention-behaviour gap. The differences in observed behaviour (the amount of money transferred in the PG game) according to gender, region and size of home town are smaller than the difference between declarations, although some declarations are associated with behaviour in the PG game. Females declare a higher willingness to cooperate, but do not display a higher level of cooperation in practice. This may be the result of a statistically higher level of aversion to risk. In the games considered, the more cooperative an action, the higher the level of risk. 
This study also presents new information about the behaviour of individuals from Central and Eastern Europe. The large majority of previous studies in this field have been conducted in the United States or Western Europe. The detailed meta-analysis carried out by Bailleit et al. does not indicate any differences in the mean level of cooperation between countries. However, this analysis only included one study from Central or Eastern Europe, conducted in Russia and based on only 24 individuals (the meta-analysis was based on a total sample size of 31,462 individuals) (Balliet et al., 2011).

Of course, although this study was carried out on a large sample, there are aspects which have not been studied (e.g. the age range of the participants in this study was small, since they were all students). Studies show that the level of cooperation also depends on the information that players are given about the other participants regarding, e.g., their sex. The fact that the majority of participants were female might affect the level of cooperation (Cadsby and Maynes, 1998). In our study, the participants could see all the others taking part in a given session, but the sex ratio in a session showed no significant association with behaviour. However, it is possible that if the participants had specific information about who they were playing with, then this would affect behaviour.

\section{Acknowledgments}

This project was financed by the National Centre for Science on the basis of decision number DEC-2012/07/B/HS5/03954.

\section{References}

Andersen, S., Bulte, E., Gneezy, U., and List, J. (2008). Do women supply more public goods than men? Preliminary experimental evidence from matrilineal and patriarchal societies (Artefactual Field Experiments No. 00108). The Field Experiments Website. Retrieved from https://ideas.repec.org/p/feb/artefa/00108.html

Andreoni, J. (1989). Giving with Impure Altruism: Applications to Charity and Ricardian Equivalence. Journal of Political Economy, 97(6), 1447-1458.

Andreoni, J., and Petrie, R. (2008). Beauty, gender and stereotypes: Evidence from laboratory experiments. Journal of Economic Psychology, 29(1), 73-93.

Balliet, D., Li, N. P., Macfarlan, S. J., and Van Vugt, M. (2011). Sex Differences in Cooperation: A Meta-Analytic Review of Social Dilemmas. Psychological Bulletin, 137(6), 881-909.

Brown-Kruse, J., and Hummels, D. (1993). Gender effects in laboratory public goods contribution: Do individuals put their money where their mouth is? Journal of Economic Behavior \& Organization, (22), 255-267.

Borghans, L., Heckman, J. J., Golsteyn, B. H. and Meijers, H. (2009). Gender differences in risk aversion and ambiguity aversion. Journal of the European Economic Association, 7(2-3), 649-658.

Cadsby, C. B., and Maynes, E. (1998). Gender and free riding in a threshold public goods game: Experimental evidence. Journal of Economic Behavior \& Organization, (34), 603-620.

Chermak, J. M., and Krause, K. (2002). Individual Response, Information, and Intergenerational Common Pool Problems. Journal of Environmental Economics and Management, 43(1), 47-70.

Croson, R., and Gneezy, U. (2009). Gender Differences in Preferences. Journal of Economic Literature, 47(2), 448-474. 
Deaux, K., and Lewis, L. L. (1984). Structure of gender stereotypes: Interrelationships among components and gender label. Journal of Personality and Social Psychology, 46(5), 9911004.

Eagly, A. H. (1987). Sex Differences in Social Behavior: A Social-role interpretation. Psychology Press.

Eagly, A. H., and Crowley, M. (1986). Gender and helping behavior: A meta-analytic review of the social psychological literature. Psychological Bulletin, (100), 283.

Eagly, A. H., and Wood, W. (1999). The origins of sex differences in human behavior: Evolved dispositions versus social roles. American Psychologist, 54(6), 408-423.

Eckel, C., and Grossman, P. J. (2008). Men, Women and Risk Aversion: Experimental Evidence". In: C. Plott and V. Smith (Eds.), Handbook of Experimental Economics Results (Vol. 1, pp. 1061-1073). New York: Elsevier.

Falk, A., and Fischbacher, U. (2006). A theory of reciprocity. Games and Economic Behavior, 54(2), 293-315.

Feingold, A. (1994). Gender differences in personality: a meta-analysis. Psychol Bull, 116(3), 429-456.

Gillian, C. (1982). In a Different Voice. Harvard University Press.

Greig, F., and Bohnet, I. (2009). Exploring gendered behavior in the field with experiments: Why public goods are provided by women in a Nairobi slum. Journal of Economic Behavior \& Organization, 70(1), 1-9.

Gunnthorsdottir, A., Houser, D., and McCabe, K. (2007). Disposition, history and contributions in public goods experiments. Journal of Economic Behavior \& Organization, 62(2), 304315.

Isaac, R. M., and Walker, J. M. (1988). Group Size Effects in Public Goods Provision: The Voluntary Contributions Mechanism. The Quarterly Journal of Economics, 103(1), 179199.

Kashima, Y., Yamaguchi, S., Kim, U., Choi, S. C., Gelfand, M. J., and Yuki, M. (1995). Culture, gender, and self: a perspective from individualism-collectivism research. Journal of Personality and Social Psychology, 69(5), 925-937.

Lewicka, M. (2013). Localism and activity as two dimensions of people-place bonding: The role of cultural capital. Journal of Environmental Psychology, 36, 43-53.

Lotito, G., Migheli, M., and Ortona, G. (2013). Is cooperation instinctive? Evidence from the response times in a public goods game. Journal of Bioeconomics, 15(2), 123-133.

Markowska-Przybyła, U., and Ramsey, D. (2014). A game theoretical study of generalised trust and reciprocation in Poland: I. Theory and experimental design. Operations Research and Decisions, (3), 59-77.

Markowska-Przybyla, U., and Ramsey, D. (2015). A game theoretical study of generalised trust and reciprocation in Poland: II. A description of the study group. Operations Research and Decisions, (2), 51-73.

Mui, V.-L. (1995). The economics of envy. Journal of Economic Behavior \& Organization, 26(3), 311-336.

Nowell, C., and Tinkler, S. (1994). The influence of gender on the provision of a public good. Journal of Economic Behavior \& Organization, (25), 25-36.

Ockenfels, A., and Bolton, G. E. (2000). ERC: A Theory of Equity, Reciprocity, and Competition. American Economic Review, 90(1), 166-193.

Oswald, D. L., Clark, E. M., and Kelly, C. M. (2004). Friendship Maintenance: An Analysis of Individual and Dyad Behaviors. Journal of Social and Clinical Psychology, 23(3), 413441. 
Rosenthal, R. W. (1973). A class of games possessing pure-strategy Nash equilibria. International Journal of Game Theory, 2(1), 65-67.

Seguino, S., Stevens, T., and Lutz, M. (1996). Gender and cooperative behavior: economic man rides alone. Feminist Economics, 2(1), 1-21.

Sell, J., Griffith, W. I., and Wilson, R. K. (1993). Are Women More Cooperative Than Men in Social Dilemmas? Social Psychology Quarterly, 56(3), 211-222.

Sell, J., and Wilson, R. K. (1991). Levels of Information and Contributions to Public Goods. Social Forces, 70(1), 107-124.

Solow, J. L., and Kirkwood, N. (2002). Group identity and gender in public goods experiments. Journal of Economic Behavior \& Organization, 48(4), 403-412. 